\title{
The Design and Implementation of Mount Lu 3D Virtual Tourism System
}

\author{
Wei Yue ${ }^{1, a}$, Chaoyang Fang ${ }^{2, b}$ \\ ${ }^{1}$ College of Geography and Environment, Jiangxi Normal University, Nanchang, Jiangxi, China \\ ${ }^{2}$ College of Geography and Environment, Jiangxi Normal University, Nanchang, Jiangxi, China \\ a570136369@qq.com, b1036213442@qq.com
}

\section{Keywords: Virtual Tourism; 3D Virtual Tourism System; Mount Lu}

Abstract. 3D virtual tourism system is a new tourism information platform supported by virtual reality technology, which provides a new opportunity for the development of tourism. It is direct, authentic, interactive, dynamic, and rich in tourism information. This paper introduces the concept and development status of 3D virtual tourism system, and then discusses the main functions of Mount $\mathrm{Lu}$ 3D virtual platform, at last develops and realizes Mount Lu 3D virtual tourism system.

\section{Introduction}

In the modern social conditions, tourism has become a necessity of the public, a way of life with universal acceptance and practice, and a kind of popular consumer goods. With the rapid development of social economy and technology, the traditional tourism industry is unable to meet people's needs. Since the middle of the 20th century, as the new technological revolution has been deepening, especially the development of virtual reality technology, computer technology, multimedia technology and network technology, the emergence of 3D virtual tourism has provided new opportunities for the development of tourism.

3D virtual tourism system is based on the reality of tourism landscape, using virtual reality technology, geographic information technology and other technologies, and integrating tourism information resources. 3D virtual tourism system is a tourism information network system of displaying natural style, historical and cultural landscape. Through the network, visitors can sit in front of the computer, choosing the tour route and visiting the tourist attractions thousands of miles away according to their own wishes. Visitors can operate the 3D tourism system on they own, visit the entire area, and have an aerial view of the whole scenic areas, which offering a stronger interaction and experience. It is a prelude to the field of tourism when visitors use the system and conduct a virtual immersive tour on the internet.

On December 6, 1996, the United Nations Educational, Scientific and Cultural elected Mount Lu landscape in the World Heritage List and gave the following remarks "with its peculiar style in historic remains, which is melted with remarkable natural beauty, Mount $\mathrm{Lu}$ has formed a highlyaesthetically-valued cultural view closely relevant to the spirit of Chinese people and their cultural life". At present, there is not a 3D, all-round way to display the Mount Lu landscape and tourism information on the internet. The traditional ways of tourist attractions publicity and display are through the text, pictures and video, which cannot reflect the characteristics of Mount Lu totally. There is an urgent need to reproduce the Mount Lu terrain on the internet, and integrate scenic spots, attractions, hotels, shopping, leisure, transportation and other tourism-related information resources based on the location. Visitors can query all kinds of travel information about eat, live, travel, travel, purchase, enjoyment in the three-dimensional scene, and arrange their own itinerary.

\section{The Development of Virtual Tourism System}

At present, some domestic universities have also started the research in this field, developing a number of relatively successful virtual roaming scenes, such as the virtual Palace Museum developed by Hangzhou University, Shuangru Mountain Tomb scenes developed by Shandong University archaeological digital museum, etc., but these systems are not integrated into a complete system. 
Another example is the "digital Wuyi" 3D tourism service system, "online Expo" and other three-dimensional virtual tourism system using virtual reality technology, reflecting the 3D real scene. These systems integrate the ancient building and hotel building model, visitors can view the scene in multiple angles. These 3D systems are a great demonstration of the characteristics of tourist attractions, but do not support entering the building model, and do not reflecting the combination of high-precision modeling, high realism display, efficient information query and other functions. Mount Lu 3D virtual tourism system integrates Mount Lu high-precision DEM and multi-temporal DOM, and visually shows Mount Lu's natural style, cultural landscape and tourism information through integrating the vector data, 3D building model and multimedia attribute data.

\section{System Design}

Construction Goal. The goal of the system is to establish 3D virtual scenes in virtual space which is of high fidelity, good user experience, ornamental, roaming, interactive, and easy to operate, using internet technology, virtual reality, 360 panorama and multimedia technology. To build a three-dimensional virtual tour system that displays Mount Lu's natural landscape, cultural landscape and tourism information, providing a virtual tourism system which is intuitive, dynamic, interactive, rich travel information. Through the system visitors can not only view the real scene of Mount Lu and query related tourism information. Meanwhile, this system plays an important role in promoting the scenic spots, attracting tourists and establishing scenic brand, and is an innovative tourist scenic marketing model.

System Architecture. The system was established based on B/ S three-tier framework structure, the three-tier framework structure is display layer, service layer and data layer in order. As shown in Figure 1.

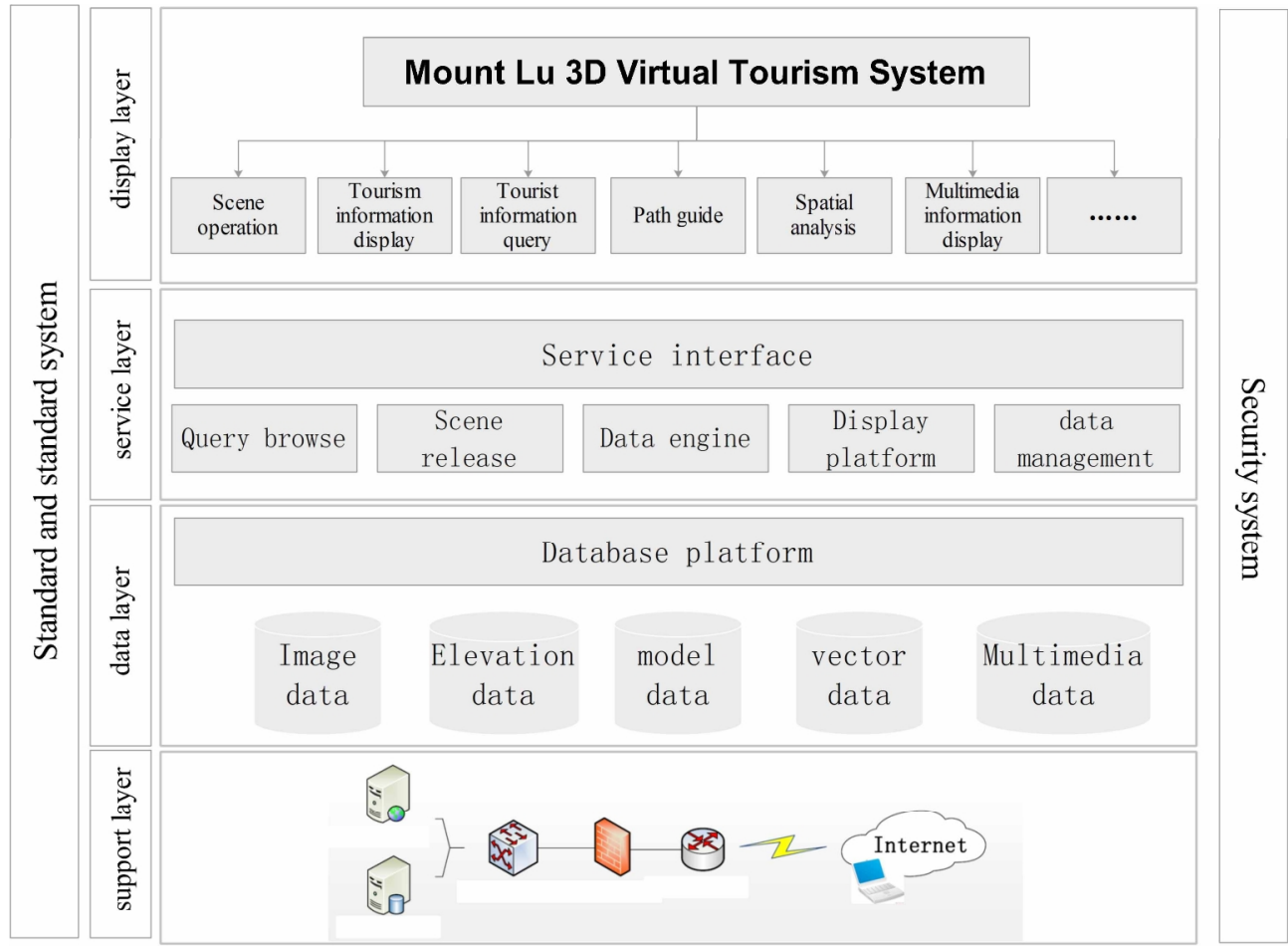

Fig. 1 system architecture

Main Functions. To meet the goal of Mount Lu 3D virtual tourism system, the main functions of the system are as follows:

Scene operation. Basic graphics operation functions meet the needs of browsing the scenes, allowing users to find the target and obtain useful information more quickly and easily from a wide range of scenarios. Its operating functions are: zoom in, zoom out, free zoom, roaming and so on.

Tourism information display. Tourism information display function is the display of $3 \mathrm{D}$ digital results for Mount Lu scenic spots and tourism products information. The high-precision DEM and 
multi-temporal DOM are used to simulate the terrain of Mount $\mathrm{Lu}$, and the main tourist attractions of Mount Lu Mountain are constructed using oblique photography technology, geometric modeling and 3D laser scanning technology. At the same time, the platform is in accordance with the food, housing, travel, shopping, entertainment and other tourism elements of tourism products based on 3D scenes of the spatial location, and uses multimedia to describe the details of scenic spots.

Tourist information query. It provides doing all categories of fuzzy search and doing geo-based peripheral search. Fuzzy query search can query all relevant information of 3D scenes through the keywords, and position the location. The information includes scenic spots, attractions information, names and other information, and the system achieves fast positioning function to the scenic spots. Such as providing convenient, intuitive, rich geographic information and inquiring traffic lines, hotels, restaurants, shopping scenes and other locations.

Path guide. The path guide provides a 3D display of convenient travel routes, itinerary, price and other information. Such as high-quality tourist routes, Self-driving routes, short-term tourist routes, etc., and at the same time provides other information related to the path, such as hotel booking, weather, traffic, specialty inquiries and so on.

Spatial analysis. In the 3D virtual tourism system there is a need to use GIS analysis tools to facilitate the user to make travel decision. In addition to locate scenic areas, measure the distance and update information, etc., the platform also provides some real three-dimensional spatial analysis functions, such as visual analysis, visibility analysis and sunshine analysis.

Multimedia information display. The function provides multimedia display of various scenic spots information and tourism products. It integrates Mount Lu scenic spots information and travel products information, designs multimedia information interactive display interface, and improves the system interaction experience.

\section{System Implementation}

Data Collection and Processing. In order to construct 3D virtual scene, the data collection and processing mainly includes the following contents:

(1) Using aerial mapping methods and processing remote sensing images, acquiring about 350 square kilometers 1: 2000 digital elevation model (DEM) and 4 quarter 1: 2000 digital orthophoto (DOM), four quarters of multi-time DOM data of Mount Lu. The combination of DEM and multi-temporal DOM data can simulate the natural landscape terrain characteristics of Mount $\mathrm{Lu}$ in different seasons and provide a basic platform for the display of other data.

(2) Using automatic modeling method to deal with tilt photography data, and producing high-precision tilt photography model data of Donglin Temple area.

(3) Fusing the point cloud data obtained by three-dimensional laser scanning and the architectural texture data obtained by field survey, and using 3dMax modeling software to establish a perfect spatial topology of the high-precision Geometric model.

(4) The tourism-related vector data and attribute information are obtained by field investigation and close-up shooting method.

3D Scene Construction. The steps for building a 3D scene are as follows:

(1) Overlaying DEM data and orthographic image DOM, and constructing to the 3D terrain scene.

(2) using modeling technology to construct cultural attractions models, including mountains, lakes, cliffs, waterfalls, caves, forests and other natural landscape and architecture, as well as roads, towers, pavilions, bridges and other cultural landscape. At present, the system integrates the 3D modeling model data such as the Catholic Church, the Bailudong Academy and the Donglin Temple tilt photography model data.

(3) Collecting and arranging Vector data such as realm data, road data, toponymic data and the tour thematic data such as scenic spots, attractions, text, pictures, video and three-dimensional panoramic, which enrich and improve the Mount Lu 3D scene. 
Database Construction. In order to facilitate the query and management of digital achievements, digital results database for cultural heritage landscape resources and cultural tourism resources is developed, achieving multi-source, multi-temporal basic geographic data and cultural heritage data integration.

System Development. The system uses SuperMap iDesktop platform to integrate and build three-dimensional scene, and uses the SuperMap iServer to release Mount Lu three-dimensional virtual scene service, and finally uses SuperMap iClient 3D to display the scenes and develop the functions to meet the needs of users. It provides a wealth of tourist information through intuitive way for the tourists. The system interfaces are shown in Figure 2.

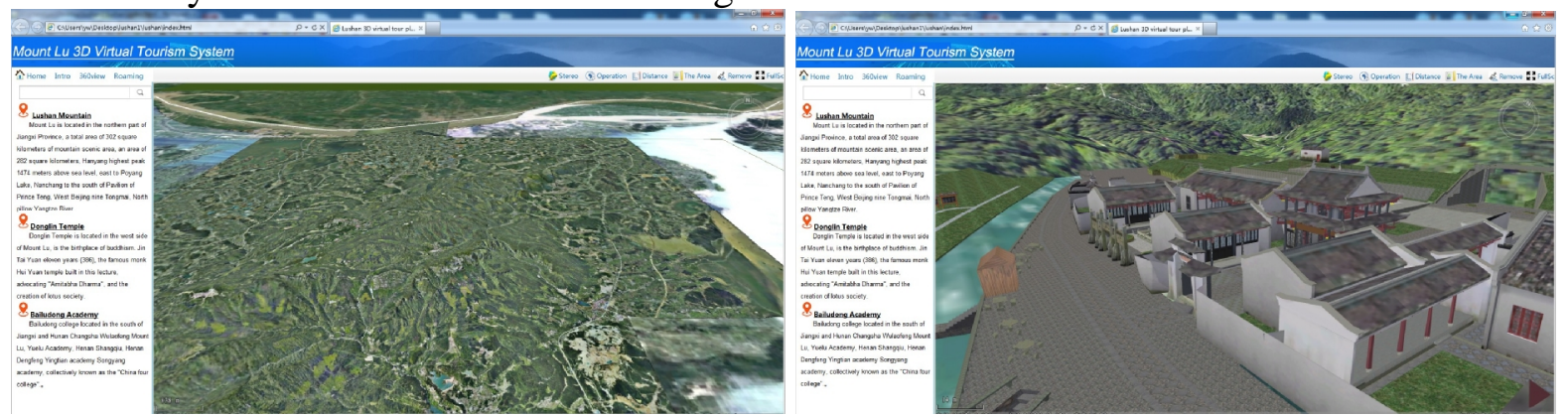

Figure 2 system interfaces

\section{Conclusions}

Mount Lu 3D virtual tourism system uses virtual reality as the main technical means, displays Mount Lu tourist attractions comprehensively, and gives visitors immersive feelings. In order to improve the modeling accuracy, the system integrates high-resolution image and high-precision digital elevation model to build a three-dimensional geospatial platform. Using the three-dimensional laser scanning point cloud data to determine the size and structure of the building, and then performing indoor $3 \mathrm{~d}$ Max modeling, labeling and baking, the original three-dimensional model is formed. After performing scene integration and feature development, visitors can stay at home to understand the relevant tourist information through the internet. Mount $\mathrm{Lu}$ 3D tourism system is not only realistic and vivid expression of Mount Lu tourist attractions of the scenery style, providing a comprehensive, rich content of three-dimensional geographic information, but also breaking the time and space, people can visit and use the system anytime and anywhere.

\section{Acknowledgements}

This work was financially supported by National Science and Technology Support Program Project (2015BAH50F03) and Jiangxi Universities Science and Technology Landing Project (KJLD14019).

\section{References}

[1] Xinli Zhang,Libin Zhao and Huijie Yan: Diffusion Processes in Advanced Technological Materials (2012), in Chinese.

[2] Fengxian Li: Science \& Technology Vision, Shanghai (2015), in Chinese.

[3] Erpin Zhao,Weiqun Zhi and Hongen Dang: Tibet Science and Technology (2012), in Chinese.

[4] Wenyan Jiang, Xiaohua Zhu and Chen Chen: Science \& Technology Review (2007), in Chinese.

[5] Fengxian Li: Journal of Shanghai Normal University (2007), in Chinese.

[6] Information on http://www.china-Mount Lu.com/en/brief.php. 